\title{
What can public health do to address inequities in infectious disease?
}

\author{
Moloughney BW ${ }^{1,2^{\star}}$
}

\section{Abstract}

Background: The recognition of the importance of social conditions informed early public health responses to infectious disease epidemics. By influencing exposure, vulnerability, and access to health services, social determinants of health (SDOH) continue to cause inequalities in infectious disease distribution. Such preventable and unjust inequalities are considered to be inequities.

Analysis: A number of challenges and barriers exist to more widespread public health action that addresses SDOH and inequities, including a lack of clarity on what public health should or could do. The National Collaborating Centre for Determinants of Health (NCCDH) has identified four primary roles for public health action on $\mathrm{SDOH}$ and inequities. This paper describes these roles and includes examples of their application to infectious diseases. The critical contribution that organizations make in providing the leadership and support for programs and staff to pursue action on $\mathrm{SDOH}$ and inequities is also highlighted.

Conclusion: While the challenge is large and complex, approaches such as the NCCDH roles for public health action provide a menu of options to facilitate the analysis and action to address $\mathrm{SDOH}$ and inequities in infectious diseases.

\section{Affiliations}

${ }^{1}$ BWM Health Consultants Inc. Newmarket, ON

${ }^{2}$ Dalla Lana School of Public Health, University of Toronto, Toronto, ON

*Correspondence: brent. moloughney@rogers.com

Suggested citation: Moloughney BW. What can public health do to address inequities in infectious disease? Can Comm Dis Rep 2016;42-Suppl 1:S14-7. https://doi.org/10.14745/ccdr.v42is1a03

\section{Introduction}

Modern public health came about in response to the epidemics that occurred after the onset of the Industrial Revolution. With mass migration to cities, poor living conditions due to overcrowded and poorly ventilated housing, contaminated drinking water and indiscriminate disposal of sewage enabled the spread of infectious diseases. The marked differences in mortality between population groups prompted the advocacy efforts of the Sanitary Movement to improve the living conditions of the poor (1).

Today, these conditions are referred to as the social determinants of health (SDOH) and defined as the "interrelated social, political and economic factors that create the conditions in which people live, learn, work and play" (2). Health inequities, in turn, are health inequalities in which the differences are associated with modifiable and unfair social disadvantages (2). From the Ottawa Charter on Health Promotion (3) to the Report on the Health of Canadians (4) to the contributions to the World Health Organization Commission on Social Determinants of Health (5), Canada has emphasized the importance of health determinants and inequities on an international scale. Nevertheless, health-care practitioners and public health organizations can struggle with identifying what exactly they should and can do to address inequities (6). While acknowledging the complexities and barriers to addressing health equity issues, this paper describes a set of roles for public health to use to address inequities in the context of infectious diseases.

\section{Analysis}

The distinction between health inequalities and inequities is important. Health inequalities refer to measurable differences in health between individuals, groups or communities (2). For example, the rate of disease $X$ in population $Y$ differs from the rate in population $Z$.

As defined earlier, health inequities are inequalities in which the differences in health are associated with modifiable social disadvantages that many consider unfair (2). Underlying the concept of health equity is a commitment to social justice and basic human rights such as access to clean water, food, education and health care (7).

One approach to thinking about how SDOH influence disease is to consider how they influence exposure, vulnerability and access to health services (8). SDOH affect all three of these aspects in the case of tuberculosis (TB), for example: they increase the risk of exposure when people live in crowded, inadequately ventilated housing; they increase vulnerability to infection when nutritional intake is inadequate; and they decrease access to health services (9). Even in a country like Canada with universal health care, access issues include the availability of health-care providers and diagnostic equipment in remote areas; payment barriers for some classes of refugee applicants; the costs of transportation and missing work to attend appointments; and the level of trust toward health-care practitioners (10). 
While TB is no longer common in Canada, the incidence rate of active TB in the Canadian-born Aboriginal population is 34 times higher than for the Canadian-born non-Aboriginal population (11). Since TB is preventable and curable, the inequality of TB rates in Aboriginal populations reflects a health inequity. Inequities for TB also exist for foreign-born individuals. For example, the extent of SDOH barriers to access to care for this population has prompted Toronto Public Health to add a social worker to its TB program to address housing, income and immigration issues (10).

Analyzing the influence of SDOH on exposure, vulnerability, and access to health services is applicable to other infectious diseases. But understanding does not guarantee action. An environmental scan conducted by the National Collaborating Centre for Determinants of Health (NCCDH) in 2010 reported a number of barriers to more widespread public health action on SDOH and inequities (6):

- lack of clarity about what public health should or could do;

- limited evidence base on what works to mitigate the effects of SDOH on health;

- $\quad$ preoccupation with behaviour and lifestyle approaches;

- bureaucratic organizational characteristics;

- limitations in organizational capacity; and

- the need for leadership, more effective communication and supportive political environments.

A key conclusion of the NCCDH scan was that while analyses of and action on health determinants and inequities are not new to public health, the approaches to address them were never institutionalized and/or were lost due to other pressures (6). To address this, the NCCDH recommended four primary roles for public health, which the Centre adopted to guide its knowledge translation work to advance SDOH and health equity through public health practice and policy (12). These roles are described below.

Assess and report on the existence and impact of health inequities and effective strategies to reduce these inequities

The role of assessing and reporting on health inequities and effective strategies to reduce their existence and impact comes most naturally to public health organizations and is fundamental to informing action for the other three roles. Recent examples applied to infectious diseases include, but are not limited to, the 2013 report from the Chief Public Health Officer of Canada, which highlights inequities in TB (11), and the City of Toronto report on health inequities, which highlights the inequities in chlamydia rates among Toronto youth (13).

Both reports provide high level guidance for steps to address the observed inequities. In the NCCDH environmental scan, many key informants indicated that public health needs to move beyond merely describing inequities to taking action and addressing them (6), which is the focus of the following three roles.
Modify and orient interventions and services to help reduce inequities, with an understanding of the unique needs of populations that experience marginalization

Understanding the unique needs of populations is about ensuring that the planning of public health interventions and services consider and address inequities. An increasingly common approach is for organizations to incorporate equity assessments into their operational planning cycles (14). An excellent example of this is Saskatoon Population and Public Health's audit of its immunization program, which detected marked differences between neighbourhoods in immunization coverage rates, with the lowest rates in lower-income neighbourhoods (15). Subsequent changes in practice, including redistributing program resources and using parent/guardian reminders, were associated with reductions in the differences in neighbourhood coverage rates (16).

Partner with other government and community organizations to identify ways to improve health outcomes for populations that experience marginalization

Due to the complex interdependencies of $\mathrm{SDOH}$, many organizations, in addition to public health, are working to address the needs of particular populations. With different mandates and perspectives, and the pervasiveness of $\mathrm{SDOH}$, service barriers and gaps can nevertheless persist. Better coordination and joint planning by system actors are needed to prevent and address such gaps. For example, in Manitoba, a Tri-Partite Table was established during and after the H1N1 pandemic between the provincial government, the federal government, the Assembly of Manitoba Chiefs, the Manitoba Métis Federation, and representatives of regional health authorities to foster better communication between and coordination among the parties, with consensus reached on many issues (17). Such partnering should lead to more lead to more effective and efficient service delivery.

Lead, support and participate with other organizations in policy analysis and development, and in advocacy for improvements in health determinants and inequities

Participating in policy development and advocacy is a key role for public health since structural change of SDOH has the greatest potential impact on the population's health (18). Policies can target one or more of the SDOH's influences on exposure, vulnerability and/or access. For example, the British Columbia Provincial Health Officer's report HIV, Stigma and Society: Tackling a Complex Epidemic and Renewing HIV Prevention of Gay and Bisexual Men in British Columbia (19) identified several subpopulations that are more vulnerable due to social, political and environmental factors. Stigma, verbal harassment and violence result in a variety of adverse health risks including increased sexual risk-taking behaviour and greater barriers to accessing appropriate health care, as well as a greater likelihood of poor mental health outcomes. The Provincial Health Officer recommends enhancing protective factors such as comprehensive and inclusive sexual health education that challenges stigma and fosters decision-making skills; improving and expanding health care for HIV-positive individuals; advancing support for mental health and substance use services; and revisiting prosecutorial guidelines to do with HIV (19). 


\section{Addressing the barriers to action}

The roles proposed by NCCDH consider what public health can do to address SDOH and inequities in health that also include infectious diseases. Despite public health's historical roots and all the knowledge about SDOH and inequities, an additional barrier to action is the perception that addressing SDOH and inequities would be "extra work" for public health organizations (6). To address this issue, jurisdictions are increasingly incorporating explicit expectations in their core programs/standards. For example, the following provincial public health programs have incorporated the mitigation of inequities into the mandate of their public health activities:

Québec Public Health Program (20)

- Key strategies include community development and participation in intersectoral action to promote health and support for vulnerable groups

A Framework for Core Functions in Public Health (BC) (21)

- Includes a "lens' through which to assess and address health inequalities

- Identifies eight ways public health can help reduce health inequalities

Ontario Public Health Standards (22)

- Identifies addressing determinants of health and reducing inequities as fundamental to the work of public health

- A key requirement is to identify and work with local populations that are a priority

Nova Scotia Public Health Standards (23)

- Incorporates the four NCCDH-defined roles (assess and report on inequities and effective strategies; modify public health interventions; partner with other health service providers; conduct policy analyses, development and advocacy) in a foundational standard.

In developing the Nova Scotia Public Health Standards, a practical challenge was identified for infectious disease prevention and control (IDPC) staff to pursue action on $\mathrm{SDOH}$ and inequities. While IDPC professionals possess key knowledge and insights to inform understanding and action on underlying $\mathrm{SDOH}$ that are driving adverse health outcomes, operational demands of day-to-day responsibilities limit the available time to pursue such actions. One suggested approach was for organizations to support these IDPC staff to provide input into $\mathrm{SDOH}$ initiatives, while dedicated staff from elsewhere in the organization, such as health promoters, could pursue longer-term actions to influence SDOH through healthy public policies and other strategies.

\section{Conclusion}

Action on $\mathrm{SDOH}$ and inequities is intrinsic to public health practice. Such action is reflected in the historical roots of public health, described in decades of landmark reports and explicitly included in core programs. While a number of barriers exist, primary public health roles for action have been identified and applied to infectious diseases and other conditions.

While action on SDOH and inequities involves individual practitioners, public health action predominantly reflects organizational level processes and outputs (6). For example, producing a report that highlights inequities or partnering with other sectors to pursue policy change requires a conscious organizational decision. Fulfilment of any of the four $\mathrm{NCCDH}$-defined roles requires leadership to establish priorities, allocate resources, model behaviours and attitudes, educate the public and decision makers and build the organization's capacity to undertake this work (6).

At the systems level, leadership and communication are also required to make public health roles and responsibilities explicit and provide the political support for public health involvement and action. While the challenge is large and complex, approaches such as the NCCDH roles for public health action provide a menu of options to facilitate the analysis and action to address $\mathrm{SDOH}$ and inequities in infectious diseases.

\section{Conflict of interest}

None.

\section{References}

1. Susser M, Stein Z. The British Sanitary

Movement: Edwin Chadwick. In: Susser M, Stein Z, editors. Eras in epidemiology: The evolution of ideas. New York: Oxford Scholarship Online; 2009.

http://www.oxfordscholarship.com/view/10.1093/acprof :oso/9780195300666.001.0001/acprof-9780195300666chapter-6.

2. National Collaborating Centre for Determinants of Health. Glossary of essential health equity terms. Antigonish (NS): NCCDH, St. Francis Xavier University; 2014. http://nccdh.ca/images/uploads/comments/English_ Glossary_Nov17_FINAL.pdf.

3. World Health Organization; Health and Welfare Canada; Canadian Public Health Association. Ottawa Charter for Health Promotion. Geneva (CH): WHO; 1986.

http://www.phac-aspc.gc.ca/ph-sp/docs/charter-chartre/ index-eng.php.

4. Federal Provincial and Territorial Advisory Committee on Population Health. Report on the Health of Canadians. Ottawa (ON): Health Canada; 1996. http://publications. gc.ca/collections/Collection/H39-385-1996-1E.pdf.

5. Commission on Social Determinants of Health. Closing the gap in a generation: health equity through action on the social determinants of health. Geneva: World Health Organization; 2008. http://www.who.int/social_ determinants/thecommission/finalreport/en/.

6. National Collaborating Centre for Determinants of Health. Integrating social determinants of health and health equity into Canadian public health practice: environmental scan 2010. Antigonish (NS): National Collaborating Centre for Determinants of Health, St. Francis Xavier University; 2010. http://nccdh.ca/images/uploads/Environ_Report_EN.pdf. 
7. National Collaborating Centre for Determinants of Health. (2013). Let's talk: Health equity. Antigonish, NS: National Collaborating Centre for Determinants of Health, St. Francis Xavier University. http://nccdh.ca/images/uploads/Lets_Talk_ Health_Equity_English.pdf.

8. Loring B, Robertson A. Obesity and inequities: Guidance for addressing inequities in overweight and obesity. Copenhagen: WHO Regional Office for Europe; 2014. http://www.euro.who.int/_data/assets/pdf_ file/0003/247638/obesity-090514.pdf.

9. Hargreaves JR, Boccia D, Evans CA, Adato M, Petticrew M, Porter JD. The social determinants of tuberculosis: From evidence to action. Am J Public Health. 2011 Apr;101(4):654-62.

10. National Collaborating Centre for Determinants of Health and National Collaborating Centre for Infectious Disease. (2014). Public Health Speaks: Tuberculosis and the Determinants of Health. Antigonish, NS: National Collaborating Centre for Determinants of Health, St. Francis Xavier University. http://nccdh.ca/images/uploads/Public Health_Speaks-_Tuberculosis_and_the_social_determinants_ of_health_Final.pdf.

11. The Chief Public Health Officer's report on the state of public health in Canada, 2013: infectious disease-the never-ending threat. Ottawa (ON): Public Health Agency of Canada; 2013. http://www.phac-aspc.gc.ca/cphorsphcrespcacsp/2013/assets/pdf/2013-eng.pdf.

12. National Collaborating Centre for Determinants of Health. Our work. Antigonish (NS): The Centre; 2015. http://nccdh. ca/our-work/.

13. van Ingen $T$, Khandour $E$, Fleiszer P. The unequal city 2015 : Income and health inequities in Toronto. Toronto (ON): Toronto Public Health; 2015. http://www.toronto.ca/legdocs/ mmis/2015/hl/bgrd/backgroundfile-79096.pdf.

14. Sudbury \& District Health Unit. The SDHU OPHS evidenceinfromed planning cycle. 2015. http://sudburyfamilies. ca/beststart/assets/File/2015PlanningCycle\%20-\%20 Appendix\%20A(3).pdf.

15. Saskatoon Health Region. Immunization report. Report of the Medical Health Officer. Saskatoon (SK): Saskatoon Health Region; 2006. https://www.saskatoonhealthregion.ca/ locations_services/Services/Health-Observatory/Documents/ Reports-Publications/ImmunizationReport2005_001.pdf.
16. Kershaw T, Cushon J, Dunlop T. Towards equity in immunization: the immunization reminders project. Saskatoon (SK): Saskatoon Health Region; 2011. http:// www.saskatoonhealthregion.ca/locations_services/Services/ Health-Observatory/Documents/Reports-Publications/ ImmRemindersProject_TwoPager_000.pdf.

17. National Collaborating Centre for Determinants of Health. Learning from practice: Equity in influenza prevention in Manitoba. Antigonish (NS): The Centre; 2015. http://nccdh. ca/images/uploads/Manitoba_EN_Feb_20.pdf.

18. Frieden TR. A framework for public health action: The health impact pyramid. Am J Public Health. 2010 Apr;100(4):590-5.

19. British Columbia Provincial Health Officer. HIV, stigma and society: Tackling a complex epidemic and renewing HIV prevention for gay and bisexual men in British Columbia. Victoria (BC): Ministry of Health; 2014. http://www2.gov. bc.ca/assets/gov/health/about-bc-s-health-care-system/ office-of-the-provincial-health-officer/reports-publications/ annual-reports/hiv-stigma-and-society.pdf.

20. Cardinal L, Francoeur D, Hamel M, Kirouac S, Théberge Y. Quebec Public Health Program 2003-2012. Quebec (QC): Ministère de la Santé et des Services sociaux; 2003. http://publications.msss.gouv.qc.ca/acrobat/f/ documentation/2003/03-216-02A.pdf.

21. Population Health and Wellness. A framework for core functions in public health: Resource document. Victoria (BC): Ministry of Health Services; 2005. http://www.health.gov. bc.ca/library/publications/year/2005/core_functions.pdf.

22. Ontario Ministry of Health and Long-Term Care. Ontario public health standards. Toronto (ON): Queen's Printer for Ontario, 2008. http://www.health.gov.on.ca/en/pro/ programs/publichealth/oph_standards/docs/ophs_2008.pdf.

23. Nova Scotia Public Health. Nova Scotia Public Health Standards 2011-2016. Halifax (NS): Nova Scotia Public Health; 2011. http://novascotia.ca/dhw/publichealth/ documents/Public_Health_Standards_EN.pdf. 